\title{
Um estudo empírico da aplicação da GQT nas empresas manufatureiras de portes médio e grande do Estado do Ceará
}

\author{
João Welliandre Carneiro Alexandre, Dr. \\ Departamento de Estatística e Matemática Aplicada/Centro de Ciências \\ Universidade Federal do Ceará \\ Campus do PICI, bloco 910 \\ CEP 60455-760 - Fortaleza - CE \\ Fone: (85) 288-9840 - Fax: (85) 288-9836 \\ jwca@ufc.br
}

\author{
José Joaquim do Amaral Ferreira, Dr. \\ Departamento de Engenharia de Produção/Escola Politécnica \\ Universidade de São Paulo \\ Av. Prof. Almeida Prado, $531-2^{\circ}$. andar - Cidade Universitária - São Paulo - SP \\ CEP 05508-900 \\ Fone: (11) 38185363 \\ jjafjuca@usp.br
}

Dentro do processo de implantação dos vários modelos da Gestão pela Qualidade Total (GQT), as organizações enfrentam desafios que afetam efetivamente o sucesso dessa implantação: resistência dos funcionários, falta de compromisso da alta administração, alocação insuficiente de recursos, relacionamento de conflito com fornecedores, etc. Nesse sentido, este artigo apresenta resultados de uma pesquisa, realizada no Estado do Ceará, cujo objetivo é investigar a aplicação das práticas da GQT nas empresas manufatureiras de portes médio e grande. Dentre as empresas pesquisadas, este trabalho revela que a aplicação das práticas da GQT é menos efetiva nas empresas cearenses, que nas empresas não-cearenses, situadas no Estado do Ceará. Uma explicação para esse fenômeno consiste no fato de que as empresas não-cearenses trazem o "know-how" tecnológico da GQT de suas matrizes e implanta-o nas suas filiais situadas no parque industrial cearense.

Palavras-chave: gestão pela qualidade total; fatores críticos de sucesso; setor manufatureiro.

During the process of implementation of Total Quality Management(TQM), the organizations face many challenges that affect the success of this implementation. The employees' resistance, lack of commitment of top management, fail to provide adequate resources, conflicting relationship with suppliers, etc... The objective, therefore of this paper, is to present the results of a survey investigating the application of TQM, in companies stablished in the State of Ceará, Brazil. Among other results it was shown that native companies are not as successful in the application of TQM as the companies that have their headquarters in other States of Brazil or abroad. There are some evidences that the know-how, brought from the main offices, explains this fact.

Keywords: total quality management; critical factors of success; manufacturing industries.

\section{Introdução}

A qualidade dos produtos ou serviços como estratégica de negócios é amplamente reconhecida como uma força no mercado competitivo, tanto no âmbito interno como externo, como nos setores públicos e privados.

As organizações estão tomando consciência de que investimento em qualidade pode ser uma questão de sobrevivência, um diferencial competitivo superior. Tal consciência está associada a fatores tais como: exigência e um maior grau de maturidade dos consumidores no que se refere aos produtos e serviços adquiridos, forte concorrência interna e externa, busca de maior eficiência nos processos internos, conquista de novos mercados, aumento de indenizações pagas judicialmente causadas por produtos e serviços com qualidade inferior. 
Dentro desse contexto, a Gestão pela Qualidade Total(GQT) insere-se como uma importante forma de gestão capaz de atender as necessidades de ambos, das organizações fornecedoras de produtos ou serviços e do exigente mercado consumidor.

Existem diversos estudos empíricos focando a aplicação da GQT em diversos setores industriais. Podemos citar: Lascelles \& Dale (1990), Main (1994), Anderson et al. (1995), Hill \& Wilkinson (1995), Hanksever (1996). Uma abordagem comum a todos esses estudos é realizarem suas análises em países desenvolvidos e/ou ambientes economicamente mais estáveis do que os ambientes que encontramos no Brasil.

Nos países em desenvolvimento, onde imperam um ambiente de incerteza e turbulência econômica, pesquisas empíricas e estudos científicos da avaliação de práticas da GQT, como diferencial competitivo, são ainda muito incipientes. Este estudo visa contribuir para o preenchimento dessa lacuna, tomando como laboratório o setor manufatureiro de portes médio e grande do Estado do Ceará (um estado pobre inserido dentro de um país em desenvolvimento).

O objetivo portanto deste trabalho é investigar como se desenvolve a implantação da GQT dentro de um ambiente onde o acesso às informações, tecnologia e recursos é precário. Buscaremos identificar, se existirem, as adaptações ou soluções alternativas utilizadas pelas empresas locais para superar as dificuldades e obter resultados.

\section{Modelos filosóficos da gestão pela qualidade total}

A criação de modelos conceituais para representar a GQT é decorrente da percepção de diferentes acadêmicos ou praticantes, na implantação dos seus fundamentos, nos diversos continentes ou países.

Dentre os pensadores clássicos podemos citar Deming, Juran, Feigenbaum, Ishikawa. Mas, ultimamente encontramos alguns pensadores modernos que conseguiram com muita clareza sintetizar o pensamento dos clássicos, acrescentando detalhes dos desenvolvimentos e resultados obtidos pelos pesquisadores contemporâneos. Dentre os que se destacam encontramos Galgano, Merli e Shiba et al. Suas visões são as seguintes:

A visão Galgano (1993) sintetiza o modelo da GQT baseado na experiência japonesa combinando princípios filosóficos, mecanismos de gerenciamento e técnicas operacionais. Esse modelo é fundamentado em quatro princípios básicos, quais sejam Premissas Básicas, Cultura da Qualidade, Processos Funda- mentais e Liderança do Máximo Dirigente.

A visão de Merli (1993) apresenta o modelo europeu de referência para a GQT baseado nas melhores experiências ocidentais e no conceito de "hierarquia de sistemas": nível estratégico, o sistema de gerenciamento, mecanismos organizacionais, ferramentas e técnicas.

Esse modelo divide a GQT em cinco sub-sistemas, inseridos em dois grupos:

Sub-sistemas específicos da GQT:

- Os Fundamentos. Formas de organização para melhorias, as ferramentas para a solução de problemas e as técnicas estatísticas.

- A Organização Operativa. Processos de gerenciamento para a localização de problemas, priorização e remoção de obstáculos e os métodos e instrumentos para executá-los.

- Políticas, Estratégias e Sistema de Gerenciamento (aspectos de gerenciamento). As políticas, as abordagens estratégicas e os métodos e instrumentos para executá-los.

Sub-sistemas relacionados com mudança organizacional para o desenvolvimento da GQT:

- Os sistemas de informações e da qualidade.

- A cultura da organização e o fator humano.

A visão de SHIBA et al. (1993) apresenta o modelo focado em quatro revoluções do pensamento administrativo americano. O modelo, segundo esses autores, é na realidade o reflexo do modelo japonês dentro do cenário dos Estados Unidos da América (EUA):

1. As organizações GQT têm "foco nos consumidores" e na satisfação de suas necessidades. Portanto, elas devem ser capazes de reagirem rapidamente às mudanças nas necessidades dos consumidores, agindo sobre os recursos disponíveis em atividades que levam a plena satisfação desses mesmos consumidores.

2. As organizações GQT perseguem a "melhoria contínua" dos processos que conduzem à alta qualidade dos produtos e serviços. A Melhoria contínua envolve o uso de abordagens científicas (análises e ações baseadas em fatos, testes dos resultados empíricos), fazendo melhorias passo a passo, buscando altos níveis de qualidade dos produtos e serviços.

3. As organizações GQT perseguem a "participação total". Todos os membros da organização devem usar de suas capacidades na busca da melhoria contínua objetivando a satisfação do consumidor. 
4. As organizações GQT devem participar do processo de "aprendizagem da sociedade", isto é, compartilhar as experiências e práticas com as outras organizações, para evitar a reinvenção de métodos, possibilitar a implantação de práticas da qualidade mais rapidamente e criar uma cultura da qualidade de se fazer negócios.

Uma visão alternativa desses modelos filosóficos são os prêmios nacionais da qualidade. Esses prêmios visam, dentro de uma abordagem geral, a promoção e reconhecimento da qualidade como uma estratégia de negócios, e a divulgação, pelas empresas vencedoras, dos resultados advindos dessas estratégicas (Reimann, 1989; DeCarlo \& Sterett, 1990; Stratton, 1990; Ghobadian \& Woo, 1996). As organizações vencedoras desses prêmios são denominadas "organizações de classe mundial", isto é, são aquelas que se destacam nas práticas de melhoria da qualidade de seus produtos e serviços e no desempenho de seus negócios. Como ilustração podem ser citados: Prêmio Deming de Aplicação(PDA) - no Japão, Malcolm Baldrige National Quality Award(MBNQA) - nos Estados Unidos da América, Prêmio Australiano da Qualidade(PAQ) - na Austrália, Prêmio Europeu da Qualidade(PEQ) - da European Foundation for Quality Management. No Brasil existe o Prêmio Nacional da Qualidade e o seu primeiro processo de premiação ocorreu ano de 1992.

\section{Os fatores críticos de sucesso da GQT}

Uma abordagem comum nos modelos conceituais descritos acima, em particular, as visões de Galgano, Merli e Shiba et al., é que eles foram elaborados a partir de experiências de diversas organizações que buscaram a filosofia da qualidade como forma de gestão.

Contudo, como identificar através de pesquisas empíricas organizacionais os fatores críticos que afetam a implantação da GQT?

Um trabalho pioneiro nessa direção é apresentado por Saraph et al. (1989) que identificam um conjunto de oito fatores críticos de sucessos na implantação da GQT: papel da alta administração e política da qualidade, registros e dados da qualidade, treinamento, relações dos empregados, gerenciamento de processo e procedimentos de operação, projeto produto e serviço, gerenciamento da qualidade do fornecedor e o papel do departamento da qualidade. Esses autores sugerem um instrumento de medição para esses fatores, constante de 66 práticas da GQT. Esse estudo foi corroborado por Badri et al. (1995) que, através de sua replicação, confirmam a confiabilidade e validade desse instrumento.
Porter \& Parker (1993) identificam 9 fatores críticos de sucesso para a implantação da GQT: conduta do gerenciamento, estratégia para a GQT, tecnologias da qualidade, gerenciamento da qualidade do processo, treinamento para a GQT, envolvimento dos empregados, comunicação para a GQT, gerenciamento de processo e sistemas e a organização para a GQT. Acrescentam que a conduta do gerenciamento liderança, visão, compromisso com a GQT - é o mais importante fator crítico.

Black \& Porter (1995), por meio de duas pesquisas empíricas, exploram os fatores críticos, primeiro, fundamentado no trabalho de Saraph et al. e, segundo, baseado no modelo de excelência da qualidade do Malcolm Baldrige National Quality Award.

Os empregados tornam-se uma fonte negativa na condução da GQT, caso o sistema de comunicação entre os departamentos não seja eficiente (Crofton \& Dale, 1996). Ngai \& Cheng (1997) afirmam que barreiras culturais, resistência, desconfiança e falta de compromisso dos empregados, treinamento e educação insuficientes, falta de um sistema de "feedback" do consumidor, falta de um sistema de recompensas, reconhecimento e medição da qualidade, pobre sistema de comunicação e compromisso e liderança da alta administração são potenciais barreiras na implantação da GQT.

Resultados semelhantes encontram-se em Tamimi \& Gershon (1995) e Tamimi (1995). Esses autores, tomando como base os 14 pontos de Deming, concluem que os fatores críticos mais importantes na implantação da GQT são o compromisso da alta administração, a liderança dos supervisores, educação, comunicação interfuncional para a melhoria da qualidade, gerenciamento do fornecedor, treinamento, inovação e garantia de recursos para os empregados.

Mann \& Kehoe (1995) investigam quais Características Organizacionais Críticas da Qualidade(COCQ) influenciam um efetivo programa de implantação da GQT. Esses autores constatam que organizações "jovens" - com pouco tempo de instalação, integradas geograficamente, cuja força de trabalho seja "jovem", com pouco tempo de serviço na organização, encontrarão menos dificuldades em abraçar a filosofia da GQT.

Soler (1997) estabelece a necessidade da introdução do componente de maturidade organizacional no processo de implantação da GQT, sob pena de esse processo resultar em fracasso e acabar com o próprio desempenho operacional da empresa. Esse autor propõe um modelo adaptativo de implantação da qualidade total, desenvolvido a partir da introdução de recomendações de ordem evolutiva, sobre a estrutura formal do processo de auto-avaliação, 
tomando como base os critérios de excelência do Prêmio Nacional da Qualidade - Brasil/1997.

\section{0 modelo de referência}

As experiências das organizações que são líderes na aplicação da GQT estão auxiliando na criação de modelos para a qualidade total. Esse fato é importante principalmente para outras organizações que estão buscando a implantação de programas da GQT, para que elas não sofram os mesmos problemas que porventura tenham ocorrido e possam definir estratégias de contorno dos fatores que afetam a implantação.

As diversas pesquisas empíricas descritas acima, como uma conclusão geral, identificam semelhantes fatores críticos que afetam a implantação da GQT nas organizações. Para efeito deste trabalho, assume-se como um dos parâmetros fundamentais de comparação na elaboração do modelo de referência a ser investigado, o estudo pioneiro proposto por Saraph et al. (1989). Conforme já citado anteriormente esse trabalho é base para diversas outras pesquisas empíricas organizacionais que investigam a aplicação das práticas da GQT. O trabalho de Black \& Porter (1995) citado acima é uma ilustração importante. Um ouro parâmetro para a definição do modelo proposto neste trabalho foi uma pesquisa anterior realizada dentro do cenário cearense. Nessa pesquisa foi aplicado a Metodologia de Delphi onde se buscou, através da opinião de especialistas, informações sobre o grau de entendimento dos conceitos relacionados à qualidade e a aplicação da GQT no Estado do Ceará. A Adaptação dos modelos já consagrados da GQT à cultura cearense e a busca de alternativas regionais da sua forma de implantação foram algumas conclusões importantes dessa pesquisa. Assim, o modelo de referência proposto leva em consideração a tentativa de buscar uma correspondência entre o modelo de Saraph et al dentro da realidade cearense. Uma abordagem comparativa dos modelos citados nessa discussão é apresentada na Tabela 1.

Como medida de desempenho da qualidade foi acrescentado no nosso estudo a variável "resultados da qualidade do produto".

Para medir cada fator crítico e resultados da qualidade foi elaborado um conjunto de medidas operacionais, isto é, práticas da GQT. Os fatores críticos são na realidade construtos que podem ser denominados de variáveis latentes, isto é, variáveis que não podem ser medidas diretamente (Hambleton \& Swaminathan, 1985; Andrade, et al., 2000). Com a finalidade de medir essas variáveis latentes as práticas da qualidade foram elaboradas em forma de sentenças positivas (para maiores detalhes ver Alexandre, 1999).

Tabela 1. O modelo de referência: uma comparação com os estudos de Saraph et al. e Black \& Porter

\begin{tabular}{|c|c|c|c|}
\hline & SARAPH et al. & BLACK \& PORTER & Modelo de Referência \\
\hline- & $\begin{array}{l}\text { O papel da alta administração e a } \\
\text { política da qualidade }\end{array}$ & $\begin{array}{l}\text { - Conduta da administração e cultura } \\
\text { da qualidade }\end{array}$ & $\begin{array}{l}\text { - Comprometimento da alta } \\
\text { administração }\end{array}$ \\
\hline- & Registros e dados da qualidade & - Dados do desempenho da qualidade & _ Mensuração da qualidade \\
\hline- & Treinamento & - Treinamento dos empregados & - $\quad$ Treinamento \\
\hline- & Relações dos empregados & $\begin{array}{l}\text { - Programas de envolvimento dos } \\
\text { empregados }\end{array}$ & $\begin{array}{l}\text { - Envolvimento dos } \\
\text { funcionários }\end{array}$ \\
\hline- & $\begin{array}{l}\text { Gerenciamento de } \\
\text { processo/procedimentos de operação }\end{array}$ & $\begin{array}{l}\text { Responsabilidades operacionais da } \\
\text { qualidade }\end{array}$ & \\
\hline- & Projeto produto/serviço & $\begin{array}{l}\text { Requerimentos operacionais da } \\
\text { qualidade }\end{array}$ & - Melhoria contínua \\
\hline- & $\begin{array}{l}\text { Gerenciamento da qualidade do } \\
\text { fornecedor }\end{array}$ & & - $\quad$ Parceria com fornecedor \\
\hline \multirow[t]{3}{*}{-} & Papel do departamento da qualidade & $\begin{array}{l}\text { - Papel operacional do departamento } \\
\text { da qualidade }\end{array}$ & \\
\hline & & 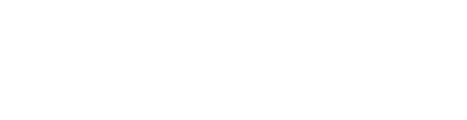 & $\begin{array}{ll}- & \text { Foco no consumidor } \\
- & \text { Empowerment } \\
- & \text { Benchmarking }\end{array}$ \\
\hline & & $\begin{array}{ll}\text { - } & \text { Estratégia externa da qualidade } \\
\text { - } & \text { Papel estratégico do departamento } \\
& \text { da qualidade }\end{array}$ & \\
\hline
\end{tabular}




\section{Método de pesquisa}

A pesquisa que trata este artigo desenvolveu-se entre os meses de agosto de 1998 a fevereiro de 1999, no Estado do Ceará, abrangendo tanto a região metropolitana da capital, Fortaleza, como o interior do Estado. Dentro do processo de amostragem selecionou-se empresas manufatureiras médias e grandes do Guia Industrial do Ceará/1998, elaborado pela Federação das Indústrias do Estado do Ceará(FIEC). Das 124 empresas médias e grandes contidas nesse guia, 108 empresas estão localizadas na Grande Fortaleza e 16 no interior do Estado do Ceará. O porte da empresa é classificado de acordo com o Instituto Brasileiro de Geografia e Estatística(IBGE): empresa de porte médio, de 100 a 499 funcionários; empresa de porte grande, de 500 ou mais funcionários.

Nas empresas localizadas na Grande Fortaleza, o processo de coleta de informações foi feito por entrevista pessoal, sendo pesquisadas 68 empresas. Quanto às do interior do Estado, em função dos elevados custos operacionais, foi por meio do correio. Dentre as 16 empresas, 4 retornaram o questionário respondido. Assim, nesse estudo, estão contidas informações de 72 empresas manufatureiras médias e grandes do Estado do Ceará, com informações coletadas, quase que totalmente, com base em entrevista pessoal.

Todo processo de agendamento, execução das entrevistas pessoais com as empresas, envio de correspondências para aquelas situadas no interior e telemarking foram executados pelos próprios pesquisadores. Acrescenta-se ainda que muitas empresas inseridas nesse guia, ou não se enquadravam no perfil do porte (empresas manufatureiras de portes médio e grande), ou se negaram a fornecer informações. Isso levou à impossibilidade de pesquisar um maior número de empresas do guia. A Tabela 2 apresentada os motivos que levaram algumas empresas a estarem fora do estudo.

Tabela 2. Motivos que levaram a não inclusão de algumas empresas

\begin{tabular}{l|c}
\hline \multicolumn{1}{c|}{ Motivos } & $\begin{array}{c}\text { Número de } \\
\text { empresas }\end{array}$ \\
\hline Empresa com menos de 100 funcionários & 10 \\
Empresa desativada & 5 \\
Empresa não-manufatura & 5 \\
Empresa que não desejaram participar & 20 \\
\hline \multicolumn{2}{c}{ Total } \\
\hline
\end{tabular}

A escala de Likert, com categorias de 1-5 (discordo totalmente, discordo parcialmente, indeciso, concordo parcialmente, concordo totalmente) foi utilizada como instrumento de registro das respostas. Essa escala, ordinal, buscava medir o nível de aplicação da GQT, com gradiente crescente de intensidade para valores altos das categorias da escala. Conforme o nível de implantação na empresa das práticas da GQT, declarado pelo entrevistado, era marcada a categoria correspondente na escala de Likert. Como uma ilustração pode ser citada a seguinte prática que mede a fator crítico Comprometimento da Alta Administração (Item 1.2 da Tabela 4): "a alta administração freqüentemente discute a importância da qualidade em suas reuniões". O funcionário da área da qualidade, diretor ou gerente industrial com visão mais abrangente da empresa foi o profissional escolhido para marcar as respostas, conforme a empresa se enquadrasse nas categorias das sentenças.

Sobre a escala de Likert é importante afirmar que:

- A escala apresenta o inconveniente da tendência de se marcar os valores altos das categorias, e uma forma de se reduzir esse vício é colocar sentenças negativas - com sentido contrário (BRYMAN, 1990). Esse artifício foi executado na elaboração do questionário desta pesquisa (itens 1.6, 3.2, $5.1 \mathrm{e}$ 6.3 da Tabela 4).

- A marcação das categorias da escala de Likert é baseada em critérios subjetivos, segundo o entendimento do entrevistado. Dessa forma, o entrevistado pode tender a marcar valores maiores baseado somente na informalidade da aplicação da GQT.

- Uma vez que a pesquisa foi quase totalmente (68 das 72 empresas pesquisadas) feita por meio de entrevista pessoal executada pelos próprios pesquisadores, pôde-se observar que a aplicação dos elementos da GQT, em sua maioria, é executada de forma não estruturada principalmente ao se considerar as empresas que declararam não ter programa formal de Gestão pela Qualidade(GQ).

Baseado nessas considerações torna-se possível afirmar que valores altos das medidas obtidos na pesquisa pode não significar, necessariamente, uma efetiva aplicação dos elementos da GQT. Na realidade essa é uma deficiência da escala de Likert. Contudo, sua utilização, neste estudo, deve-se a sua larga aplicação em pesquisas organizacionais e principalmente ao fato de que para a execução da pesquisa era necessário um instrumento que representasse uma escala acumulativa de implantação das práticas da GQT. Uma alternativa talvez fosse a utilização de questões dicotômicas, do tipo SIM ou NÃO. Todavia, isso além de aumentar o vício nas respostas, uma vez que as respostas retratariam ainda menos a realidade da situação das empresas, os resultados não se prestariam a determinação das medidas estatísticas efetuadas neste trabalho (principalmente a média e desvio padrão). 


\section{Resultados e análises}

Um resultado inicial obtido pela pesquisa é que dentre as 72 empresas pesquisadas 38 declararam que tinham programas formais de gestão pela qualidade (baseados na sua maioria na GQT ou na ISO 9000), enquanto que 32 empresas afirmaram que não tinham.

A Tabela 3 apresenta a relação das indústrias pesquisadas segundo o porte e o ramo de atividade. Essa tabela mostra que, dentre as 72 empresas pesquisadas, 50 são de porte médio e 22 são de grande porte. Há uma predominância do setor de Vestuário (15 empresas) e Produtos Alimentares (14 empresas).

\subsection{Análise dos fatores críticos de sucesso da GQT}

Nesta seção é feita uma análise de cada elemento da GQT pesquisado, incluindo resultados da qualidade. Esses resultados então na Tabela 4 apresentada abaixo. Essa análise é fundamentada nas observações colhidas junto dos entrevistados, nas médias de cada elemento da GQT e nas médias das medidas operacionais definidas para medir esses elementos. $\mathrm{O}$ fato das entrevistas pessoais terem sido executadas pelos próprios pesquisadores possibilitou a obtenção de informações adicionais não reveladas pelos números, muito embora questões nesse sentido não tenham sido inseridas no questionário. Assim, as análises obtidas a partir das declarações feitas pelos entrevistados durante as entrevistas estão incluídas neste estudo.

A utilização das médias quer sejam dos fatores críticos de utilização de distribuições aproximadas (como, por exemplo, a distribuição $t$-student), uma vez que não são utilizados os dados originais. Como ilustração podem ser citados os trabalhos de Tamimi et al. (1995), Badri et al. (1995), Tamimi \& Gershon (1995) e Wiele et al. (1996).

- Nas empresas pesquisadas pode se afirmar que existe um comprometimento relativamente alto da alta administração para a importância da qualidade como estratégia de negócios, visto que os valores das médias estão mais próximos da categoria cinco da escala - média geral $(3,81)$ do elemento 1 (comprometimento da alta administração). Esse comprometimento está associado à definição das metas da qualidade (média 3,54 do item 1.4), efetiva divulgação do comprometimento pela qualidade a todos os níveis da organização (média 3,56 do item 1.6) e alocação de recursos para a melhoria da qualidade (média 3,57 do item 1.3). Convém acrescentar que segundo declarações de alguns entrevistados, esses recursos são, em várias empresas, alocados de acordo com as necessidades mais imediatas, e não baseadas em um planejamento estratégico.

- Um fato positivo revelado pela pesquisa é que existe uma preocupação das empresas em utilizar as informações dos consumidores como base para a melhoria da qualidade (média 4,01 do item 2.3 do elemento 2 - foco no consumidor). Há também uma preocupação em enviar as reclamações dos clientes a todos os departamentos da empresa (média 3,01 do item 2.2). É importante acrescentar que há um hiato entre o desejo de satisfazer o consumidor e um efetivo método para a obtenção de evidências objetivas para a identificação das necessidades desse consumidor. Essa afirmação baseia-se na baixa média $(2,94)$ obtida no item 2.5 , relativa a execução de pesquisas periódicas junto ao consumidor.

- A pesquisa revela que existe uma forte preocupação com qualidade e preço como critérios para a seleção de fornecedores - média 4,33 do item 3.1 do elemento 3 (parceria com fornecedor). Contudo, o relacionamento com os esses fornecedores não está baseado no longo prazo - item 3.2 com a menor média $(2,29)$. Alguns entrevistados afirmaram que em suas empresas não há contratos firmados de forma escrita e, sim, verbalmente.

- A não existência de um sistema efetivo de reconhecimento e recompensas não financeiras percebe-se através da baixa média $(2,21)$ do item 4.5 do elemento 4 - envolvimento dos funcionários. Segundo declarações de muitas empresas, o que existe na realidade é a predominância de prêmios financeiros baseados na produtividade. As reuniões em cada área de trabalho (item 4.1) não caracterizam os CCQ de Ishikawa, uma vez que, principalmente nas empresas de porte médio, as reuniões absorvem todos os funcionários da área e os problemas referentes à qualidade são incorporados a outros tipos de problemas.

- Fatores econômicos tais como a recessão e a instabilidade econômica, próprias de regiões subdesenvolvidas são algumas causas, segundo declarações de vários entrevistados, que resultam no baixo investimento em treinamento - média $(2,76)$ do item 5.1 do elemento 5 (treinamento). Os resultados dos itens 5.4 - treinamento em ferramentas estatísticas (média de 2,29) e 5.3 treinamento em técnicas de soluções de problemas (média de 2,56) confirmam essa conclusão. A pesquisa revela também que $48(66,7 \%)$ das empresas pesquisadas estimam menos de 30 horas/ ano para o treinamento em qualidade, que envolve tanto o treinamento na filosofia da qualidade como na execução de tarefas. O que se percebe, comparando os resultados deste fator com os resultados do fator comprometimento da alta 
Tabela 3. Distribuição do número de empresas por porte e ramos de atividades

\begin{tabular}{|c|c|c|c|}
\hline \multirow{2}{*}{ Ramos de Atividades } & \multicolumn{2}{|c|}{ Porte } & \multirow{2}{*}{$\begin{array}{l}\text { Total } \\
\text { Geral }\end{array}$} \\
\hline & Médio & Grande & \\
\hline 1. Vestuário, Calçados, Artefatos de Tecidos, & 11 & 4 & 15 \\
\hline 2. Produtos Alimentares & 8 & 6 & 14 \\
\hline 3. Produtos de Minerais Não-Metálicos & 8 & 1 & 9 \\
\hline 4. Metalúrgica & 8 & 1 & 9 \\
\hline 5. Têxtil & 1 & 7 & 8 \\
\hline 6. Material Elétrico e de Comunicação & 2 & 1 & 3 \\
\hline 7. Mecânica & 2 & 1 & 3 \\
\hline 8. Bebidas & 2 & 1 & 3 \\
\hline 9. Produtos Farmacêuticos e Veterinários & 2 & - & 2 \\
\hline 10. Mobiliário & 1 & - & 1 \\
\hline 11. Química & 1 & - & 1 \\
\hline 12. Perfumaria, Sabões e Velas & 1 & - & 1 \\
\hline 13. Editorial e Gráfica & 1 & - & 1 \\
\hline 14. Siderúrgica & 1 & - & 1 \\
\hline 15. Indústrias Diversas & 1 & - & 1 \\
\hline TOTAL & 50 & 22 & 72 \\
\hline
\end{tabular}

administração, é que em muitas empresas pesquisadas existe o descompasso entre o discurso proferido pela alta administração e a efetiva tomada de medidas e desdobramentos de ações para os níveis inferiores: o comprometimento da alta administração com a alocação de verbas para a qualidade não é refletido no efetivo investimento em treinamento aos funcionários.

- Uma forma de se conseguir um maior envolvimento dos funcionários nos assuntos relacionados à qualidade é manter um procedimento efetivo de divulgação, a toda organização, das avaliações referentes à qualidade. Tal premissa é muito incipiente nas empresas pesquisadas (média 2,71 do item 6.5 do elemento 6 - mensuração da qualidade). É importante afirmar que no item 6.1 obtém-se a maior média $(4,32)$, porque ele referese, tanto a existência de inspeções por amostragem, como de inspeções massivas durante o processo de produção. O interesse maior desta pesquisa consiste em avaliar a existência ou não de uma avaliação da qualidade durante o processo de produção.

- O elemento 7 (melhoria contínua) é uma evidência em favor da afirmação da existência de um sistema pouco estruturado na aplicação dos elementos da GQT. As menores médias obtidas foram $(2,71)$ do item 7.2, e $(2,97)$ do item 7.4 que correspondem, respectivamente, a existência de um programa formal para a redução de tempo e custos em todos os processos internos, e para a redução do tempo de entrega dos produtos. Muito embora a média do item 7.5 seja (3.33), o qual se refere a existência de um programa formal para a redução do tempo de fabricação dos produtos, várias empresas informaram nas entrevistas que esse fato ocorre de maneira informal (não documentado).

- Os resultados revelam uma forte evidência da necessidade das empresas pesquisadas despertarem para o benchmarking (elemento 8). A maior média
$(2,99)$, obtida no item 8.1 , relaciona-se com visitas a outras empresas realizadas de forma não sistemática, segundo declaração da maioria dos entrevistados. Muitas empresas afirmaram que o fator mais crítico que afeta diretamente a aplicação do benchmarking é a forte concorrência, o que conduz a uma relação de desconfiança com os competidores. Não é comum a prática de interação com outros setores produtivos. Para alguns entrevistados benchmarking "é uma forma eufemística de se definir espionagem industrial”.

- As experiências de sucesso na solução de problemas ficam mais limitadas ao nível da área de trabalho, segundo informações colhidas em várias empresas - menor média $(2,94)$ do item 9.4 do elemento 9 (empowerment). Na realidade o discurso de apoio aos funcionários para a solução de problemas - média 4,07 (item 9.2) se contradiz com o efetivo apoio da alta administração, uma vez que existe pouco treinamento em ferramentas estatísticas e técnicas para a solução de problemas, conforme já discutido acima. A delegação de poderes concentra-se nas áreas de chefias setoriais das empresas.

- Sobre os resultados da qualidade do produto elemento 10, muitos entrevistados declararam que há uma independência entre maior qualidade do produto e maior lucratividade - menor média $(3,47)$ do item 10.3. Isso se deve, segundo eles, a fatores externos tais como competição desleal e a crise econômica (em muitas situações é preferível reduzir as margens de lucro para se manter no mercado). Uma outra observação importante refere-se ao item 10.6 - custos referentes à qualidade: alguns entrevistados declararam que na realidade esses custos aumentaram em função de ambos, maior exigência do consumidor e o Código de Defesa do Consumidor. Isso levou algumas empresas a um crescente investimento na compra de equipamentos e no treinamento em qualidade aos funcionários. 
Tabela 4. Descrição geral das percentagens de aplicações e das médias das respostas dos elementos da GQT

\section{ELEMENTOS DA GQT/DESCRIÇÃO DAS PRÁTICAS}

1. Comprometimento da alta administração

1.1 Avaliação Periódica da qualidade executada pela alta administração

1.2 Discussão da importância da qualidade pela alta administração

1.3 Alocação de verbas e recursos para a qualidade definidos em orçamento

1.4 Definição(identificação) e documentação das metas da qualidade

1.5 As metas da qualidade inseridas no planejamento estratégico da empresa

1.6 Comunicação ativa da alta administração do compromisso pela qualidade

2. Foco no consumidor:

2.1 Comparação da satisfação do cliente com indicadores internos/concorrentes

2.2 Fornecimento das reclamações dos consumidores a todos os departamentos

2.3 Utilização das reclamações do cliente como base para a melhoria da qualidade

2.4 Manutenção de um serviço de atendimento ao consumidor

2.5 Realização periódica de pesquisas junto ao consumidor

\begin{tabular}{|c|c|c|c|c|c|}
\hline \multicolumn{5}{|c|}{ Percentagens das Respostas } & \multirow{3}{*}{ Média } \\
\hline Discordo & Discordo & Indeciso & Concordo & Concordo & \\
\hline & & muectso & & & \\
\hline 1,4 & 16,7 & 9,7 & 31,9 & 40,3 & 3,93 \\
\hline 0,0 & 9,7 & 9,7 & 26,4 & 54,2 & 4,25 \\
\hline 12,5 & 16,7 & 4,2 & 34,7 & 31,9 & 3,57 \\
\hline 11,1 & 15,3 & 12,5 & 30,6 & 30,6 & 3,54 \\
\hline 5,6 & 8,3 & 12,5 & 29,2 & 44,4 & 3,99 \\
\hline 2,8 & 31,9 & 6,9 & 23,6 & 34,7 & 3,56 \\
\hline & & & Média & Geral & 3,81 \\
\hline
\end{tabular}

\section{Parceria com o fornecedor:}

3.1 Qualidade e preço como critérios para a seleção do fornecedor

3.2 Realização de contratos de longo prazo com fornecedor 3.3 Fornecimento de assistência técnica ao fornecedor

3.4 Participação do fornecedor no processo de desenvolvimento e fabricação

\begin{tabular}{|c|c|c|c|c|c}
\hline 5,6 & 9,7 & 18,1 & 41,7 & 25,0 & 3,71 \\
\hline 8,3 & 31,9 & 15,3 & 25,0 & 19,4 & 3,15 \\
\hline 5,6 & 8,3 & 4,2 & 43,1 & 38,9 & 4,01 \\
\hline 16,7 & 13,9 & 8,3 & 27,8 & 33,3 & 3,47 \\
\hline 19,4 & 25,0 & 16,7 & \multicolumn{4}{|c}{19,4} & 19,4 & 2,94 \\
\cline { 4 - 7 } & & & \multicolumn{4}{|c}{ Média Geral } & $\mathbf{3 , 4 6}$ \\
\hline
\end{tabular}

\section{Envolvimento dos funcionários}

4.1 Realização periódica de reuniões em cada área para discussão sobre qualidade

4.2 Reuniões periódicas de equipes inter-funcionais $\mathrm{p} /{ }$ discussão sobre qualidade

4.3 Avaliação de todas as sugestões dos funcionários

4.4 Implantação das sugestões dos funcionários

4.5 Prêmios/recompensas não financeiras pelas melhores sugestões

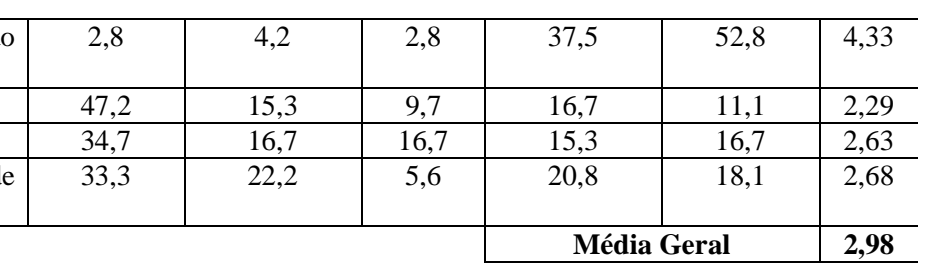

\section{ELEMENTOS DA GQT/DESCRIÇÃO DAS PRÁTICAS}

5. Treinamento

5.1 Alocação de recursos necessários para o treinamento em qualidade

5.2 Envolvimento de todos os escalões no treinamento em qualidade

5.3 Treinamento de muitos funcionários em técnicas de solução de problemas

5.4 Treinamento dos funcionários em ferramentas/técnicas estatísticas

\begin{tabular}{|c|c|c|c|c|c}
\hline 12,5 & 26,4 & 13,9 & 29,2 & 18,1 & 3,14 \\
\hline 6,9 & 18,1 & 16,7 & 30,6 & 27,8 & 3,54 \\
\hline 1,4 & 16,7 & 13,9 & 33,3 & 34,7 & 3,83 \\
\hline 4,2 & 13,9 & 12,5 & 43,1 & 26,4 & 3,74 \\
\hline 52,8 & 18,1 & 2,8 & 8,3 & 18,1 & 2,21 \\
\hline
\end{tabular}

Percentagens das Respostas

\begin{tabular}{|c|c|c|c|c|c|}
\hline \multicolumn{5}{|c|}{ Percentagens das Respostas } & \multirow[b]{2}{*}{ Média } \\
\hline $\begin{array}{l}\text { Discordo } \\
\text { Totalmente }\end{array}$ & $\begin{array}{c}\text { Discordo } \\
\text { Parcialmente }\end{array}$ & Indeciso & $\begin{array}{c}\text { Concordo } \\
\text { Parcialmente }\end{array}$ & $\begin{array}{l}\text { Concordo } \\
\text { Totalmente }\end{array}$ & \\
\hline 30,6 & 20,8 & 12,5 & 13,9 & 22,2 & 2,76 \\
\hline 13,9 & 13,9 & 8,3 & 34,7 & 29,2 & 3,51 \\
\hline 36,1 & 20,8 & 9,7 & 18,1 & 15,3 & 2,56 \\
\hline 37,5 & 30,6 & 6,9 & 15,3 & 9,7 & 2,29 \\
\hline & & & \multicolumn{2}{|c|}{ Média Geral } & 2,78 \\
\hline
\end{tabular}

\section{Mensuração da qualidade}

6.1 Execução de inspeções por amostragem durante processo de produção

6.2 Avaliação da qualidade não executada somente com inspeção final

6.3 Medição periódica dos desperdícios e falhas de produto não-conforme

6.4 Manutenção de registros das avaliações da qualidade

6.5 Fornecimento dos resultados das avaliações a todos os

\begin{tabular}{|c|c|c|c|c|c}
\hline 4,2 & 9,7 & 2,8 & 16,7 & 66,7 & 4,32 \\
\hline 9,7 & 9,7 & 0,0 & 13,9 & 66,7 & 4,18 \\
\hline 4,2 & 11,1 & 1,4 & 31,9 & 51,4 & 4,15 \\
\hline 4,2 & 9,7 & 15,3 & 33,3 & 37,5 & 3,90 \\
\hline 12,5 & 43,1 & 16,7 & 16,7 & 11,1 & 2,71 \\
\hline
\end{tabular}


7. Melhoria contínua

\begin{tabular}{|c|c|c|c|c|c|c|}
\hline \multicolumn{4}{|l|}{ 7. Melhoria contínua } & & & \multirow[b]{2}{*}{3,22} \\
\hline $\begin{array}{l}\text { 7.1 Manutenção de estrutura organizacional específica para } \\
\text { apoiar a Qualidade }\end{array}$ & 19,4 & 18,1 & 12,5 & 20,8 & 29,2 & \\
\hline $\begin{array}{l}\text { 7.2 Há programa formal para a redução de tempo e custo } \\
\text { nos processos internos }\end{array}$ & 26,4 & 25,0 & 13,9 & 20,8 & 13,9 & 2,71 \\
\hline $\begin{array}{l}7.3 \text { Execução de avaliações nos processos chaves de } \\
\text { produção }\end{array}$ & 2,8 & 16,7 & 11,1 & 38,9 & 30,6 & 3,78 \\
\hline $\begin{array}{l}\text { 7.4 Há um programa formal para a redução do tempo de } \\
\text { entrega de produto }\end{array}$ & 15,3 & 27,8 & 13,9 & 30,6 & 12,5 & 2,97 \\
\hline $\begin{array}{l}\text { 7.5 Há um programa formal para a redução do tempo de } \\
\text { fabricação }\end{array}$ & 12,5 & 16,7 & 18,1 & 30,6 & 22,2 & 3,33 \\
\hline & \multicolumn{2}{|c|}{ Média Geral } & $\mathbf{3 , 2 0}$ \\
\hline 8. Benchmarking & & & \\
\hline 8.1 Visita em outras organizações reconhecidamente líderes & 23,6 & 23,6 & 8,3 & 19,4 & 25,0 & 2,99 \\
\hline $\begin{array}{l}8.2 \text { Efetivo procedimento de benchmarking dos } \\
\text { competidores mais fortes }\end{array}$ & 27,8 & 30,6 & 16,7 & 13,9 & 11,1 & 2,50 \\
\hline $\begin{array}{l}\text { 8.3 Efetivo procedimento de benchmarking com líderes não } \\
\text { competidores }\end{array}$ & 45,8 & 29,2 & 5,6 & 11,1 & 8,3 & 2,07 \\
\hline \multirow[t]{2}{*}{$\begin{array}{l}\text { 8.4 Manutenção efetiva do benchmarking como uma política } \\
\text { da empresa }\end{array}$} & 25,0 & 16,7 & 15,3 & 25,0 & 18,1 & 2,94 \\
\hline & & & & \multicolumn{2}{|c|}{ Média Geral } & 2,63 \\
\hline \multirow[b]{2}{*}{ ELEMENTOS DA GQT/DESCRIÇÃO DAS PRÁTICAS } & \multicolumn{5}{|c|}{ Percentagens das Respostas } & \multirow{3}{*}{ Média } \\
\hline & \multirow[t]{2}{*}{$\begin{array}{c}\text { Discordo } \\
\text { Totalmente }\end{array}$} & \multirow[t]{2}{*}{$\begin{array}{c}\text { Discordo } \\
\text { Parcialmente }\end{array}$} & \multirow[t]{2}{*}{ Indeciso } & \multirow[t]{2}{*}{$\begin{array}{c}\text { Concordo } \\
\text { Parcialmente }\end{array}$} & \multirow[t]{2}{*}{$\begin{array}{l}\text { Concordo } \\
\text { Totalmente }\end{array}$} & \\
\hline 9. Empowerment (delegação de poderes aos funcionários) & & & & & & \\
\hline $\begin{array}{l}\text { 9.1 Delegação de poderes aos funcionários para a solução de } \\
\text { problemas }\end{array}$ & 4,2 & 15,3 & 11,1 & 40,3 & 29,2 & 3,75 \\
\hline $\begin{array}{l}\text { 9.2 Fornecimento de apoio aos funcionários para a solução } \\
\text { de problemas }\end{array}$ & 0,0 & 9,7 & 9,7 & 44,4 & 36,1 & 4,07 \\
\hline $\begin{array}{l}\text { 9.3 Inspeção da qualidade executada pelos funcionários (não } \\
\text { por um inspetor) }\end{array}$ & 13,9 & 12,5 & 18,1 & 29,2 & 26,4 & 3,42 \\
\hline $\begin{array}{l}9.4 \text { Divulgação das experiências de sucesso na solução de } \\
\text { problemas }\end{array}$ & 16,7 & 26,4 & 19,4 & 20,8 & 16,7 & 2,94 \\
\hline \multirow{2}{*}{\multicolumn{4}{|c|}{ 10. Resultados da qualidade do produto }} & \multicolumn{2}{|c|}{ Média Geral } & $\mathbf{3 , 5 5}$ \\
\hline & & & & & & \\
\hline 10.1 Aumento significativo da produtividade & 0,0 & 6,9 & 12,5 & 36,1 & 44,4 & 4,18 \\
\hline 10.2 Redução significativa de erros e desperdícios & 0,0 & 8,3 & 13,9 & 47,2 & 30,6 & 4,00 \\
\hline 10.3 Aumento considerável da lucratividade & 6,9 & 11,1 & 27,8 & 36,1 & 18,1 & 3,47 \\
\hline 10.4 Aumento significativo da posição competitiva & 1,4 & 8,3 & 16,7 & 38,9 & 34,7 & 3,97 \\
\hline $\begin{array}{l}10.5 \text { Redução significativa no número de reclamações dos } \\
\text { consumidores }\end{array}$ & 1,4 & 8,3 & 11,1 & 41,7 & 37,5 & 4,06 \\
\hline $\begin{array}{l}10.6 \text { Diminuição significativa dos custos referentes à } \\
\text { qualidade }\end{array}$ & 1,4 & 15,3 & 20,8 & 44,4 & 18,1 & 3,63 \\
\hline & & & & \multicolumn{2}{|c|}{ Média Geral } & $\mathbf{3 , 8 8}$ \\
\hline
\end{tabular}

NOTA: O valor "média geral" corresponde a média aritmética das varáveis(sentenças) de cada elemento calculada utilizando os dados originais.

\subsection{Análise da utilização de ferramentas estatísticas para a qualidade}

Para análise da utilização de ferramentas estatísticas para a qualidade foram utilizadas medidas relacionadas ao número e percentagens de empresas que utilizam as ferramentas definidas na pesquisa. Foram aplicados, também, testes estatísticos para fazer comparações entre as percentagens de aplicação (teste paramétrico para comparações de proporções (Costa Neto, 1977)), considerando o porte da empresa, existência de programas de GQ, e a origem das empresas.

Para nortear essa análise foram definidas as seguintes hipóteses:
Hipótese 1: As empresas de porte grande aplicam mais intensamente as ferramentas estatísticas para a qualidade, que as empresas de porte médio.

Hipótese 2: As empresas com programas de GQ aplicam mais intensamente as ferramentas estatísticas para a qualidade, que as empresas sem programas de GQ.

Hipótese 3: As empresas não-cearenses aplicam mais intensamente as ferramentas estatísticas para a qualidade que as empresas cearenses (denominase como empresa não-cearense aquela sediada no Estado de Ceará com origem em outros estados estados das Regiões Sul e Sudeste, como por exemplo). 
A Tabela 5 apresenta a distribuição da aplicação dessas ferramentas, como também os valores das estatísticas do teste para as análises das hipóteses acima.

Em termos da utilização dessas ferramentas, a Tabela 5 mostra um resultado bastante importante: as empresas cearenses pesquisadas que não têm programas formais de GQ apresentam as menores percentagens de utilização, exceto para tabelas (distribuição de frequiências) das empresas de porte médio. Essa afirmação vem corroborar o fato de que uma empresa para tomar as suas decisões, deve fundamentar-se em fatos e dados e essa característica não se evidencia em empresa que não têm programas de GT.

Em uma abordagem geral, a utilização das ferramentas estatísticas é ainda incipiente. Ao se tomar as 72 empresas (coluna GERAL da Tabela 5) observa-se que as maiores percentagens correspondem a $59,7 \%$ (43 empresas) para gráficos (coluna, setor, etc.) e $52,8 \%$ (38 empresas) para folhas de verificação. Todas as outras percentagens concentram-se entre $6,9 \%$ (5 empresas) para diagrama de dispersão e 40,3\% (29 empresas) para tabelas/distribuição de frequiências.

Uma análise das estatísticas dos testes (unilaterais) revela para:

1. Hipótese 1: Estatisticamente, ao nível de $1 \%$ de significância, as empresas de porte grande aplicam mais intensamente as seguintes ferramentas estatísticas para a qualidade, que as empresas de médio porte: diagrama de causa-e-efeito, diagrama de dispersão e estratificação. Para diagrama de $\mathrm{Pa}$ reto, tabelas/distribuição de freqüências e diagrama de fluxo de processo, a significância é de $5 \%$.
2. Hipótese 2: Ao nível de 1\% de significância, as empresas com programas de GQ aplicam mais intensamente as seguintes ferramentas da qualidade, que as empresas que declararam não ter programas de GQ: diagrama de Pareto, gráficos de controle, diagrama de causa-e-efeito, estratificação, histogramas, diagrama de fluxo de processo. A significância é ao nível de 5\% para a ferramenta diagrama de dispersão. Mesmo para as ferramentas folhas de verificação, tabelas (distribuição de frequiências) e gráficos (coluna, setor, etc.) o resultado não seja significativo, o valor da estatística é positivo. Esta conclusão reforça, estatisticamente, a afirmação de que empresas com programas de GQ aplicam de forma mais intensa as ferramentas da qualidade, que as empresas sem programas de GQ, conforme já comentado acima.

3. Hipótese 3: As empresas não-cearenses têm superioridade, estatisticamente ao nível de $1 \%$ de confiança, sobre as cearenses, na ferramenta diagrama de causa-e-efeito. Para diagrama de Pareto e gráficos (coluna, setor, etc.), a significância é de $5 \%$.

Uma análise conjunta dessas três hipóteses leva a seguinte interpretação: somente dois valores da estatística do teste foram negativos - diagrama de dispersão e folhas de verificação, na comparação entre origem das empresas não-cearenses com cearenses. Todos os outros valores foram positivos revelando, mesmo que em alguns casos estatisticamente não significantes, superioridade das empresas de porte grande sobre o médio, empresas com programas de GQ sobre as empresas sem programas, e empresas não-cearenses sobre as cearenses.

Tabela 5. Distribuição do número, percentagens (valores dos parênteses) e testes comparativos da utilização de ferramentas básicas da qualidade

\begin{tabular}{|c|c|c|c|c|c|c|c|c|c|c|}
\hline \multirow[t]{2}{*}{$\begin{array}{c}\text { FERRAMENTAS DA } \\
\text { QUALIDADE }\end{array}$} & \multirow[b]{2}{*}{ GERAL } & \multicolumn{2}{|c|}{ PORTE } & \multirow[t]{2}{*}{$\begin{array}{l}\text { Estatística } \\
\text { do Teste }\end{array}$} & \multicolumn{2}{|c|}{$\begin{array}{l}\text { PROGRAMA DE } \\
\text { GQ }\end{array}$} & \multirow[t]{2}{*}{$\begin{array}{c}\text { Estatística } \\
\text { do Teste }\end{array}$} & \multicolumn{2}{|c|}{ ORIGEM } & \multirow[t]{2}{*}{$\begin{array}{c}\text { Estatística } \\
\text { do Teste }\end{array}$} \\
\hline & & $\begin{array}{c}\text { Grande } \\
n=22\end{array}$ & $\begin{array}{c}\text { Médio } \\
\mathrm{n}=50\end{array}$ & & $\underset{\mathrm{n}=38}{\mathrm{Sim}}$ & $\begin{array}{l}\text { Não } \\
n=34\end{array}$ & & $\begin{array}{c}\text { Não- } \\
\text { Cearense } \\
n=16\end{array}$ & $\begin{array}{c}\text { Cearense } \\
n=56\end{array}$ & \\
\hline 1. Diagrama de Pareto & $21(29,2)$ & $10(45,5)$ & $11(22,0)$ & $2,02(2)$ & $18(47,4)$ & $3(8,8)$ & $3,60(1)$ & $8(50,0)$ & $13(23,2)$ & $2,08(2)$ \\
\hline 2. Gráficos de Controle & $27(37,5)$ & $10(45,5)$ & $17(34,0)$ & 0.93 & $24(63,2)$ & $3(8,8)$ & $4,76(1)$ & $8(50,0)$ & $19(33,9)$ & $\mathbf{1 , 1 7}$ \\
\hline 3. Diagrama de Causa-e- & $23(31,9)$ & $14(63,6)$ & $9(18,0)$ & 3,77 (1) & $22(57,9)$ & $1(2,9)$ & $5,00(1)$ & $9(56,3)$ & $14(25,0)$ & 2,37 (1) \\
\hline 4. Diagrama de Dispersão & $5(6,9)$ & $4(18,2)$ & $1(2,0)$ & $2,50(1)$ & $5(13,2)$ & $0(0,0)$ & $2,21(2)$ & $1(6,3)$ & $4(7,1)$ & $-1,55$ \\
\hline 5. Estratificação & $13(18,1)$ & $8(36,4)$ & $5(10,0)$ & $2,68(1)$ & $12(31,6)$ & $1(2,9)$ & $3,16(1)$ & $6(37,5)$ & $7(12,5)$ & $\mathbf{0 , 0 3}$ \\
\hline 6. Histogramas & $16(22,2)$ & $7(31,8)$ & $9(18,0)$ & 1,30 & $14(36,8)$ & $2(5,9)$ & $3,15(1)$ & $5(31,3)$ & $11(19,6)$ & 0,99 \\
\hline 7. Folhas de Verificação & $38(52,8)$ & $12(54,5)$ & $26(52,0)$ & $\mathbf{0 , 2 0}$ & $23(60,5)$ & $15(44,1)$ & 1,39 & $8(50,0)$ & $30(53,6)$ & $-0,25$ \\
\hline 8. Tabelas/Dist. & $29(40,3)$ & $13(59,1)$ & $16(32,0)$ & $2,16(2)$ & $17(44,7)$ & $12(35,3)$ & $\mathbf{1 , 1 2}$ & $8(50,0)$ & $21(37,5)$ & $\mathbf{0 , 9 0}$ \\
\hline 9. Gráficos & $43(59,7)$ & $16(72,7)$ & $27(54,0)$ & 1,49 & $26(68,4)$ & $17(50,0)$ & $\mathbf{1 , 5 9}$ & $13(81,3)$ & $30(53,6)$ & $1,99(2)$ \\
\hline 10. Diagrama Fluxo de & $27(37,5)$ & $12(54,5)$ & $15(30,0)$ & $1,98(2)$ & $23(60,5)$ & $4(11,8)$ & $5,87(1)$ & $8(50,0)$ & $19(33,9)$ & $\mathbf{1 , 4 1}$ \\
\hline
\end{tabular}




\begin{tabular}{ll|c|c|c|c|c}
\hline \multirow{2}{*}{ ELEMENTOS DA GQT } & \multicolumn{2}{|c|}{$\begin{array}{c}\text { Empresa Grande } \\
\text { Porte }\end{array}$} & \multicolumn{2}{c|}{$\begin{array}{c}\text { Empresa Médio } \\
\text { Porte }\end{array}$} & \multirow{2}{*}{ Valor da } \\
\cline { 3 - 6 } & Média & $\begin{array}{c}\text { Desvio } \\
\text { Padrão }\end{array}$ & Média & $\begin{array}{c}\text { Desvio } \\
\text { Padrão }\end{array}$ & \\
Estatística t \\
\hline 1. & Comprometimento da Alta & 4,48 & 0,56 & 3,51 & 1,04 & $5,15(1)$ \\
\hline 2. & Foco no Consumidor & 3,85 & 0,84 & 3,28 & 0,86 & $2,64(1)$ \\
\hline 3. Parceria com Fornecedor & 3,19 & 0,91 & 2,89 & 0,84 & 1,38 \\
\hline 4. & Envolvimento dos Funcionários & 3,48 & 0,82 & 3,21 & 0,92 & 1,20 \\
\hline 5. & Treinamento & 3,31 & 0,96 & 2,55 & 1,19 & $2,63(1)$ \\
\hline 6. & Mensuração da Qualidade & 4,24 & 0,45 & 3,69 & 0,89 & $3,48(1)$ \\
\hline 7. & Melhoria Contínua & 3,55 & 0,95 & 3,05 & 0,95 & $2,09(2)$ \\
\hline 8. & Benchmarking & 2,65 & 1,31 & 2,62 & 1,10 & 0,11 \\
\hline 9. & Empowerment & 3,42 & 0,94 & 3,60 & 0,84 & $-0,80$ \\
\hline 10. Resultados da Qualidade do Produto & 4,17 & 0,57 & 3,76 & 0,73 & $2,32(2)$ \\
\hline
\end{tabular}

(1) Significativo a $1 \%$

(2) Significativo a 5\%

\subsection{Análise da aplicação dos fatores críti- cos de sucesso da GQT}

Para essa análise foi utilizado o teste $t$-student. A medida que representa cada elemento da GQT, como também o desempenho da qualidade do produto, é sua respectiva média aritmética, e a dispersão é representada pelo desvio padrão. É importante comentar que esse processo dentro da escala de Likert tem larga aplicação em pesquisas organizacionais. Como ilustração podem ser citados os trabalhos de Tamimi et al. (1995), Badri et al. (1995), Tamimi e Gershon (1995) e Wiele et al. (1996). É aplicado também o teste Qui-quadrado para testar independência entre estratos. Os testes $t$ student e Qui-quadrado têm sido freqüentemente utilizados em pesquisas dessa natureza: Powell (1995), Ahire (1996), Ahire et al. (1996) e Huq \& Stolen (1998). Maiores detalhes sobre estes testes podem ser vistos em Snedecor \& Cochran (1967), e Costa Neto (1977).

Hipótese 4: As empresas manufatureiras cearenses de grande porte aplicam de forma mais intensa os elementos da GQT e têm desempenho superior, que as empresas manufatureiras cearenses de médio porte.

Para verificação dessa hipótese executou-se um teste t-student (unilateral), comparando as diferenças de médias de cada elemento da GQT e do resultado da qualidade do produto, entre as empresas de porte médio (50 empresas) e grande (22 empresas), conforme descrito na Tabela 6 .

Com o teste, conclui-se que, estatisticamente ao nível de $1 \%$ de significância, as empresas manufatureiras de porte grande aplicam mais intensamente aos elementos comprometimento da alta administração, foco no consumidor, treinamento e mensuração da qualidade, que as empresas de médio porte. Quanto à melhoria contínua essa significância é de 5\%. Esse teste revela também que o desempenho dos resultados da qualidade é superior, estatisticamente, nas empresas de grande porte, ao nível de 5\% de significância. Esse último resultado corrobora a afirmação que o maior desempenho na qualidade está associado positivamente a maior implantação das práticas da gestão pela qualidade total.

O porte da empresa é um fator de influência na busca de programas de GQ, nas empresas manufatureiras pesquisadas (17 entre as 22 empresas de grande porte têm programas de GQ, enquanto somente 21 entre as 50 empresas de médio porte têm programas de GQ).

Essa conclusão é confirmada por meio da aplicação de um teste Qui-quadrado para verificar a seguinte hipótese:

Hipótese 5: Existe independência entre o porte da empresa (médio e grande) e a busca por programas de GQ. 
Essa hipótese é rejeitada, ao nível de significância de $1 \%$, de acordo com o teste (valor da estatística do teste $=7,63$, Tabela 7). Isso significa que há uma dependência entre o porte da empresa e aplicação de programas de GQ. Na realidade, como mostra a Figura 1, as empresas de grande porte têm superioridade na aplicação de programas de GQ sobre as empresas de médio porte.

Hipótese 6: Existe diferenças entre empresas cearenses e não-cearenses quanto a aplicação dos elementos da GQT e desempenho da qualidade.

Entre as 72 empresas pesquisadas 56 são cearenses e 16 não-cearenses.

De acordo com a Tabela 8 (teste $t$-student bilateral) existem diferenças estatisticamente significativas ao nível de $1 \%$ nos elementos foco no consumidor, parceria com fornecedor e treinamento. Nos elementos, melhoria contínua, benchmarking e resultados da qualidade do produto essa diferença está ao nível de $5 \%$. Muito embora nos outros elementos o teste não revele uma diferença significativa, todas as médias referentes às empresas não-cearenses são superiores. Uma informação a ser considerada é que das 56 empresas cearenses pesquisadas 30 não têm programas de GQ e entre as 16 empresas não-cearenses, 12 têm programas de GQ. Isto parece explicar o fato das empresas cearenses estarem em estágio menos avançado do que as empresas não-cearenses nas aplicações das práticas da GQT e no desempenho da qualidade do produto.

Tabela 7. Teste de Qui-quadrado para independência entre porte das empresas e existência de programas de GQ

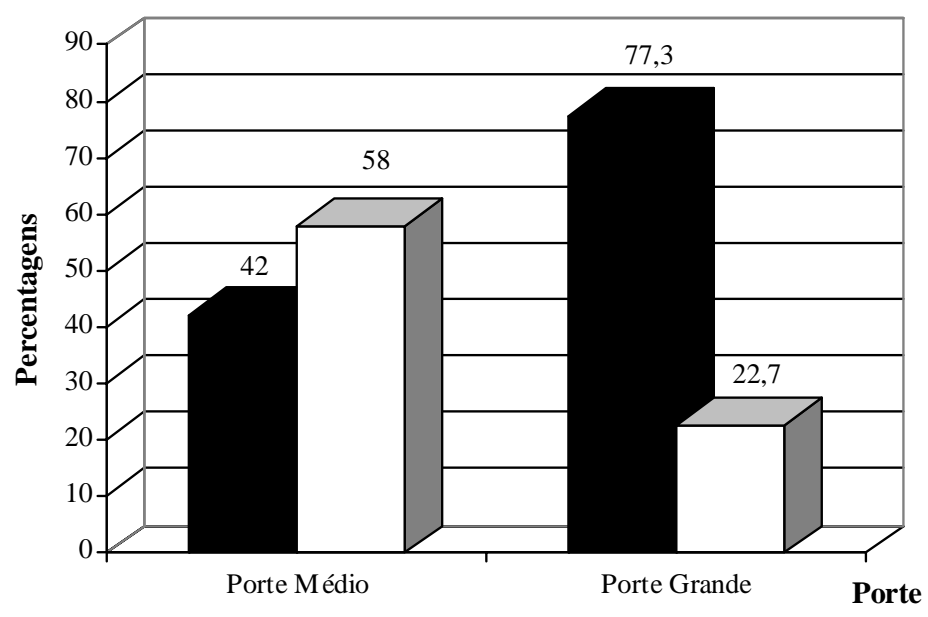

Tem Programa GQ $\square$ Não Tem Programa GQ

Figura 1. Distribuição das percentagens das empresas quanto ao porte e existência de programas de GQ

Para melhor corroborar essas conclusões foi realizado um teste Qui-quadrado para se testar a seguinte hipótese:

Hipótese 7: Existe independência entre origem das empresas (cearenses e não-cearenses) e busca por programas de GQ.
Essa hipótese é rejeitada ao nível de significância de $5 \%$ de acordo com o teste (valor da estatística do teste $=4,08$, Tabela 9). Isso significa que, estatisticamente, existe uma dependência entre origem das empresas e aplicação de programa de GQ, revelando a conclusão de que parece existir uma superioridade na aplicação de programas de GQ das empresas nãocearenses sobre as cearenses (melhor visualizado na Figura 2). 
Alexandre, João W. C.; Ferreira, José J. do A.. - Um estudo empírico da aplicação da GQT ...

Tabela 8. Teste para comparação de médias, considerando a origem da empresa

\begin{tabular}{|c|c|c|c|c|c|}
\hline \multirow[t]{2}{*}{ ELEMENTOS DA GQT } & \multicolumn{2}{|c|}{ Empresa Cearense } & \multicolumn{2}{|c|}{$\begin{array}{c}\text { Empresa } \\
\text { Não-Cearense }\end{array}$} & \multirow{2}{*}{$\begin{array}{c}\text { Valor da } \\
\text { Estatística } t\end{array}$} \\
\hline & Média & $\begin{array}{l}\text { Desvio } \\
\text { Padrão }\end{array}$ & Média & \begin{tabular}{|l|} 
Desvio \\
Padrão
\end{tabular} & \\
\hline 1. Comprometimento da Alta & 3,72 & 1,04 & 4,10 & 0,93 & $-1,33$ \\
\hline 2. Foco no Consumidor & 3,26 & 0,86 & 4,16 & 0,57 & $-4,93(1)$ \\
\hline 3. Parceria com Fornecedor & 2,81 & 0,86 & 3,58 & 0,58 & $-3,33(1)$ \\
\hline 4. Envolvimento dos Funcionários & 3,24 & 0,93 & 3,46 & 0,79 & $-0,86$ \\
\hline 5. Treinamento & 2,58 & 1,14 & 3,48 & 1,03 & $-2,86(1)$ \\
\hline 6. Mensuração da Qualidade & 3,76 & 0,83 & 4,19 & 0,71 & $-1,87$ \\
\hline 7. Melhoria Contínua & 3,08 & 0,91 & 3,63 & 1,09 & $-2,02(2)$ \\
\hline 8. Benchmarking & 2,46 & 1,09 & 3,19 & 1,26 & $-2,27(2)$ \\
\hline 9. Empowerment & 3,48 & 0,90 & 3,77 & 0,75 & $-1,15$ \\
\hline 10. Resultados da Qualidade do Produto & 3,79 & 0,72 & 4,23 & 0,56 & $-2,29(2)$ \\
\hline
\end{tabular}

(1) Significativo a $1 \%$

(2) Significativo a $5 \%$

Tabela 9. Teste de Qui-quadrado para independência entre a origem das empresas e a existência de programas de GQ

\begin{tabular}{c|c|c|c|c}
\hline \multirow{2}{*}{$\begin{array}{c}\text { Origem das } \\
\text { Indústrias }\end{array}$} & \multicolumn{2}{|c|}{ Programas de GQ } & Total & $\begin{array}{c}\text { Valor da Estatística } \\
\text { Qui-quadrado }\end{array}$ \\
\cline { 2 - 3 } & Tem & Não Tem & & \multirow{2}{*}{$4,08(1)$} \\
\hline Cearenses & 26 & 30 & 56 & 16 \\
\hline Não-Cearenses & 12 & 4 & 72 & \\
\hline Total & 38 & 34 & & \\
\hline
\end{tabular}

(1) Significativo a $5 \%$

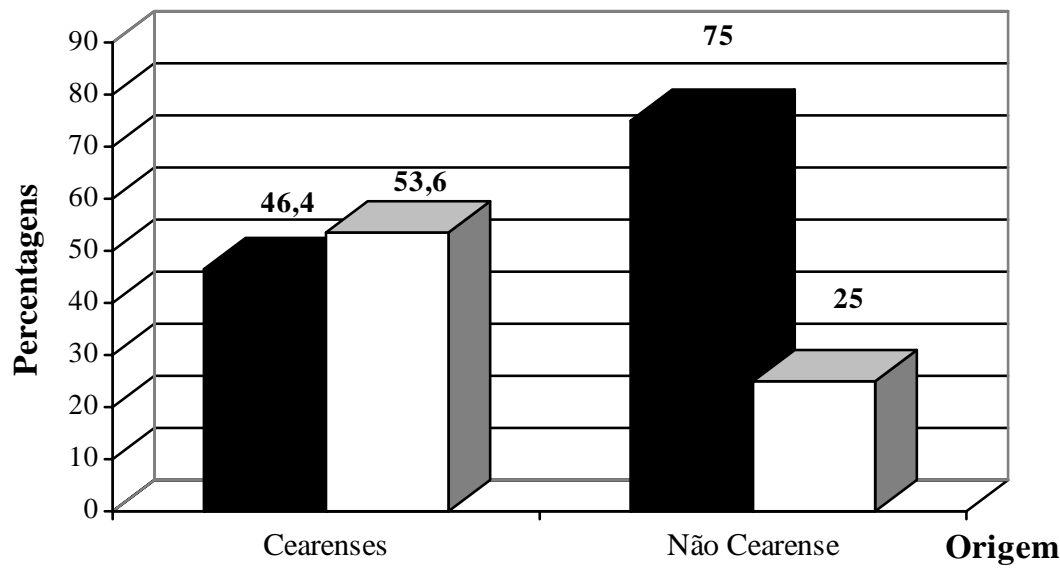

Tem Programa GQ $\square$ Não Tem Programa GQ

Figura 2: Distribuição das percentagens das empresas quanto à origem e existência de programas de GQ 
Uma possível explicação para esse fenômeno pode ser conseqüência da estratégia política agressiva do Governo do Estado do Ceará, no incentivo de instalações de novas empresas no estado, para proporcionar maior crescimento econômico e do parque industrial cearense. Muitas dessas empresas, originadas, em sua maioria, das Regiões Sul e Sudeste, centros mais avançados economicamente, trazem o know-how tecnológico de suas matrizes, e aplicam em suas filiais sediadas no Estado do Ceará. Possivelmente esse fato pode servir como um ponto positivo, um incentivo para que as empresas cearenses busquem a implantação de programas de GQ.

\section{Conclusões e comentários finais}

- Uma efetiva divulgação das avaliações da qualidade a todos os departamentos e funcionários parece ser um ponto crítico dentro das empresas pesquisadas. A pesquisa revela que essas informações são fornecidas basicamente para os setores diretamente envolvidos com os problemas da qualidade (um fator que pode limitar o enfoque sistêmico na implantação de programas de GQ). Essa concentração de informações pode certamente restringir o envolvimento de todos os funcionários nos programas de GQ, uma vez que esses funcionários podem se sentir marginalizados dentro do processo criando, assim, conflitos dentro da empresa.

- O modelo de reconhecimento é fortemente baseado em prêmios financeiros fornecidos através do sistema de quotas de produtividade. Não existe, em grande parte das empresas pesquisadas, um modelo estruturado para a captação e avaliação das sugestões dos funcionários. Esse processo dáse, em sua maioria, de maneira verbal.

- As bases para um relacionamento de parceria entre empresa e fornecedor estão ainda muito frágeis. Relacionamento de curto prazo é o que predomina. Contudo, é pertinente acrescentar que essa conclusão sofre uma influência do ramo de atividade da indústria. Como ilustração pode ser citado o setor de beneficiamento de castanha de caju, cujos fornecedores são produtores de castanhas e o relacionamento é em muitos casos, sazonal e dependente da safra. Um outro aspecto interessante revelado pela pesquisa refere-se quando o fornecedor é uma empresa grande inserida num mercado de poucas opções (monopolizado): nesta situação a parceira empresa e fornecedor torna-se ainda mais comprometida pelo poder de atuação do fornecedor no mercado.

- O binômio entre treinamento e ferramentas estatísticas para a qualidade precisa ser intensifica- do, principalmente no que se refere à utilização pelas empresas das ferramentas para solução de problemas tais como diagrama de Pareto (utilizado por 29,2\% das empresas pesquisadas), diagrama de causa e feito (por 31,9\% das empresas). As maiores percentagens de aplicação para gráficos (coluna, setor, etc) com 59,7\%, folhas de verificação com $52,8 \%$ e tabelas (distribuição de freqüências) com 40,3\% indicam que as técnicas estatísticas são mais utilizadas como "apresentação" de resultados da qualidade. A baixa utilização de ferramentas estatísticas parece ser conseqüência do baixo nível de treinamento nessas ferramentas.

- Benchmarking é o elemento da GQT mais crítico nas empresas pesquisadas (menor média geral = 2,63, correspondente a 40,8\% de aplicação). Um dos fatores que causam essa baixa aplicação é o sentimento de não cooperação e forte competição entre os setores. O que ocorre na realidade é a imperativa necessidade de domínio tecnológico como uma forma de se manter no mercado. As práticas de benchmarking concentram-se em visitas de forma não sistemáticas a outras empresas e a investigação dos produtos dos concorrentes.

- O caráter pouco formal na definição dos procedimentos revelado pelo elemento melhoria contínua pode ser um fator de redução no processo de avanço na melhoria da qualidade dos produtos. A manutenção dos níveis atuais de qualidade parece ser uma conseqüência natural desse processo.

- As empresas cearenses têm menor desempenho da qualidade e aplicam de forma menos intensa os elementos da GQT, que as empresas não-cearenses instaladas no Estado do Ceará. Possivelmente esse cenário tende a se modificar, uma vez que instituições de classes, como por exemplo, a Federação das Indústrias do Estado do Ceará - FIEC, vêm desenvolvendo importante papel na disseminação da filosofia da gestão pela qualidade.

Um aspecto a ser abordado é quanto à generalização estatística dos resultados. Assume-se, neste trabalho, que o processo de amostragem é probabilístico. Sendo, assim, os testes podem ser executados. Em pesquisas organizacionais quantitativas, amostragem probabilística é sempre preferível que amostragem não-probabilística. Contudo, há fortes limitações na sua execução. Como ilustração, suponha-se que é definido um plano amostral probabilístico e cujo método de coleta de informações é via-correio. Estudos revelam que, nesse caso, há o retorno de um número menor de questionários, o que descaracteriza assim o plano inicialmente definido, e a amostragem por voluntários (não-probabilística) torna-se o termo mais adequado.

Barreiras iniciais que influenciam na implantação de 
programas de GQ, tais como cultura organizacional para a qualidade e monopólio de mercado, não foram investigados nesta pesquisa.

A pesquisa revelou a existência de várias empresas familiares. A hereditariedade na direção e gestão centralizadora parecem ser características predominantes nesses tipos de empresas. É razoável supor, portanto, que os fatores críticos de sucessos na implantação da gestão pela qualidade diferem entre empresas familiares e não-familiares. Uma investigação nesse sentido contribuirá para a adoção de ações de contorno que visem superar possíveis resistências.

Por fim, é importante comentar que as respostas dos questionários deste trabalho são relativas às percepções de um único entrevistado que representava a empresa. Isso é conseqüência de limitações próprias de pesquisas organizacionais como, por exemplo, a dificuldade de acesso. Contudo, futuras pesquisas envolvendo diferentes opiniões de funcionários das empresas cearenses tornam-se necessárias para melhor corroborar esses resultados.

\section{Referências bibliográficas}

AHIRE, S.; WALLER, M. A. \& GOLHAR, D. Y. Quality in TQM versus no-TQM firms: an empirical investigation. International Journal of Quality \& Reliability Management, v. 13, n. 8, p. 8-27, 1996.

AHIRE, S. L. TQM age versus quality: an empirical investigation. Production and Inventory Management Journal, first quarter, v. 37, n.1, p. 18-23, 1996.

ALEXANDRE, J. W. C. Uma investigação das práticas da gestão da qualidade total no setor manufatureiro do estado do Ceará. São Paulo, 1999. Tese (Doutorado). Departamento de Engenharia de Produção - Politécnica - USP.

ANDERSON, J. C.; RUNGTUSANATHAM, M.; SCHROEDER, R. G. \& DEVARAJ, S. A path analytic model of a theory of quality management underlying the Deming management method: prelymanary emperical findings. Decision Sciences, september/october, v. 26, n. 5, p. 637-65, 1995.

ANDRADE, D. F.; TAVARES, H. R. \& VALLE, R. C. Teoria da resposta ao item: conceitos e aplicações. São Paulo, 14․ SINAPE, ABE-Associação Brasileira de Estatística, 2000. 